\title{
Managing resistant hypertension: focus on mineralocorticoid-receptor antagonists
}

\author{
This article was published in the following Dove Press journal: \\ Vascular Health and Risk Management \\ 16 October 2017 \\ Number of times this article has been viewed
}

\author{
Juan Carlos Yugar-Toledo' \\ Rodrigo Modolo ${ }^{2}$ \\ Ana Paula de Faria ${ }^{2}$ \\ Heitor Moreno ${ }^{2}$ \\ 'São José do Rio Preto Medicine \\ School - FAMERP, São José do Rio \\ Preto, ${ }^{2}$ School of Medical Sciences, \\ University of Campinas (UNICAMP), \\ Campinas, Brazil
}

\begin{abstract}
Mineralocorticoid-receptor antagonists (MRAs) have proven to be effective in some types of hypertension, especially in resistant hypertension (RHTN). In this phenotype of hypertension, the renin-angiotensin-aldosterone pathway plays an important role, with MRAs being especially effective in reducing blood pressure. In this review, we show the relevance of aldosterone in RHTN, as well as some clinical characteristics of this condition and the main concepts involving its pathophysiology and cardiovascular damage. We analyzed the mechanisms of action and clinical effects of two current MRAs - spironolactone and eplerenone - both of which are useful in RHTN, with special attention to the former. RHTN represents a significant minority $(10 \%-15 \%)$ of hypertension cases. However, primary-care physicians, cardiologists, nephrologists, neurologists, and geriatricians face this health problem on a daily basis. MRAs are likely one of the best pharmacological options in RHTN patients; however, they are still underused.
\end{abstract}

Keywords: resistant hypertension, aldosterone, aldosteronism, mineralocorticoid-receptor antagonists, spironolactone, eplerenone

\section{Introduction}

The association between arterial hypertension (HTN) and primary aldosteronism (PA) has been investigated for over 50 years. The first reported case was a patient with severe HTN and hypokalemia associated with elevated aldosterone secretion. In this patient, HTN was cured by adrenalectomy. ${ }^{1}$ From this initial finding, researchers sought to establish a cause-and-effect association between HTN and elevated plasma aldosterone levels. ${ }^{2}$ Although the PA that accompanies Conn's syndrome is well defined as a cause of secondary HTN, many aspects related to the pathophysiology, prevalence, and relevance of this association in the absence of a tumor mass detectable by conventional diagnostic methods are being discussed in research centers worldwide. ${ }^{3-6}$ For decades, researchers have demonstrated varying degrees of association between $\mathrm{HTN}$ and PA, ${ }^{7-14}$ especially the clinical presentation in normokalemia, first described in $1965 .{ }^{15}$ Subsequently, evidence suggested an important role of aldosterone in the pathophysiological mechanism of target-organ damage observed in hypertensive disease. ${ }^{16,17}$ Many authors have shown a relationship between aldosterone and left-ventricular hypertrophy (LVH), renal injury, vascular disease, ${ }^{18-25}$ atrial flutter and atrial fibrillation, ${ }^{26}$ and structural and functional alterations of medium-caliber arteries, ${ }^{27,28}$ as well as microcirculation injuries and alterations in endothelial function. ${ }^{29-35}$

In 2002, Calhoun et $\mathrm{al}^{36}$ found a PA prevalence of $20 \%$ in resistant hypertensive subjects submitted to high sodium intake ( $>200 \mathrm{mEq} / 24$ hours) with renin dosage $>12 \mu \mathrm{g} / 24$ hours or under renin suppression $(<1 \mathrm{ng} \cdot \mathrm{mL} /$ hour $)$. Gallay et al reported a
Correspondence: Heitor Moreno School of Medical Sciences, University of Campinas (UNICAMP), Rua Tessália Vieira de Camargo, 126 Cidade Universitária Zeferino Vaz, Barão Geraldo, Campinas, São Paulo I3083-887, Brazil

Email hmoreno@uol.com.br 
PA prevalence of $17 \%$ in resistant hypertensive patients in Seattle (WA, USA) based on a high aldosterone:renin ratio (ARR). ${ }^{37}$ Likewise, researchers from the Czech Republic showed that $19 \%$ of patients referred for treatment for moderate-severe HTN presented PA. ${ }^{38}$ Researchers in Oslo found a prevalence of $23 \%$ of the same condition in resistant hypertensive subjects, ${ }^{39}$ thereby confirming higher PA prevalence in individuals with resistant HTN (RHTN) than in the general hypertensive population.

In recent systematic reviews and meta-regression analyses, authors have demonstrated a wide range of prevalence in primary-care centers $(3.2 \%-12.7 \%)$ and HTN referral centers $(1 \%-29.8 \%) .{ }^{40}$ Moreover, data on patients with RHTN in five studies reported on the relationship between PA prevalence and HTN severity. Because of the heterogeneity of PA prevalence, further multicenter studies with standardized screening and a confirmation test are necessary. On the other hand, there is no robust evidence that mineralocorticoid-receptor antagonists (MRAs) prevent more cardiovascular events in RHTN patients than other antihypertensive drugs.

In 2008, the American Heart Association defined RHTN as "... blood pressure [BP] that remains above goal in spite of the concurrent use of three antihypertensive agents of different classes. Ideally, one of the three agents should be a diuretic and all agents should be prescribed at optimal dose amounts". ${ }^{41}$ In addition, patients, who require four or more medications to control $\mathrm{BP}$ are considered resistant to treatment. Almost a decade later, besides the required thiazide diuretic, angiotensinconverting-enzyme (ACE) inhibitors, angiotensin-receptor blockers (ARBs), and calcium-channel blockers probably constitute the "gold trio" in the treatment of RHTN.

The complex pathophysiology of RHTN involves multiple mechanisms, including hyperactivity of the renin-angiotensin-aldosterone system (RAAS) and the sympathetic nervous system, volume overload, endothelial dysfunction, and lifestyle factors. However, no specific fourth-line drug is recommended for RHTN treatment, although five antihypertensive drug classes (MRAs, $\alpha_{1}$-adrenergic antagonists, $\alpha_{2}$-adrenergic agonists, $\beta$-blockers, and peripheral vasodilators) are suggested as alternatives. In addition, the increased aldosterone and plasma volume in RHTN patients suggest that aldosterone antagonists should be the fourth drug for this condition. In light of the growing clinical benefits reported in RHTN, the mechanisms of action and effects of aldosterone antagonists deserve attention and are summarized herein.

\section{Aldosterone in the cardiovascular system in RHTN BP control}

Many observational studies have linked aldosterone excess to lack of BP control in RHTN subjects. This is a clinical condition different from PA, which is a secondary cause of HTN. In RHTN, Pimenta et $\mathrm{al}^{42}$ showed that patients with elevated 24-hour urinary aldosterone excretion presented sustained increases in 24-hour ambulatory BP, including nocturnal BP levels. Furthermore, these authors highlighted an interesting aldosterone-age interaction in relation to 24-hour systolic BP: as subjects with high ARR got older, systolic BP also increased by as much as 20 or $30 \mathrm{mmHg}$. Some authors have also indicated that a subpopulation of RHTN - uncontrolled subjects (currently referred to as refractory hypertensive patients $)^{43}$ - present increases in circulating levels of aldosterone, ${ }^{44-46}$ which supports the relationship between aldosteronism and poor BP control. However, previous studies suggested that this association might be driven by overactivity of the sympathetic nervous system, ${ }^{47,48}$ another common pathophysiology mechanism underlying RHTN. ${ }^{49,50}$ Finally, a phenomenon named "aldosterone escape" was described in patients treated with ACE inhibitors or ARBs. ${ }^{51,52}$ Aldosterone escape is a condition where after an initial decline, plasma aldosterone levels increase above those identified prior to treatment. This increase neutralizes the benefits of BP reductions and the cardiovascular and renal protection obtained with antihypertensive therapy provided by RAAS blockers, ${ }^{53}$ which suggests a need for MRAs ${ }^{54}$ for proper BP control.

\section{Hypervolemia and cardiac effects}

RHTN patients have concomitant intravascular volume expansion in addition to the ARR elevation, despite an extensive use of diuretics. ${ }^{55}$ Similar findings supporting the involvement of intravascular volume expansion in the pathophysiology of RHTN have been reported by researchers at the Mayo Clinic using thoracic impedance. ${ }^{56}$ However, increased intravascular volume is not limited to patients with measurable evidence of aldosterone excess, which suggests that other factors may contribute to fluid retention or that conventional evaluation of aldosterone levels may not accurately reflect its functional role in respect to blood volume. In fact, other important regulators, such as sympathetic outflow and plasma renin, participate in the balance of sodium and fluid in RHTN. However, aldosteronism contributes to heart-volume overload in RHTN individuals, despite the use of diuretics, leading to greater 
$\mathrm{LVH},{ }^{57-60} \mathrm{LV}$ diastolic dysfunction, ${ }^{52}$ and increased incidence of cardiovascular events, ${ }^{61}$ including myocardial infarction, stroke, and arrhythmia. ${ }^{62}$ Additionally, experimental studies have shown that excessive aldosterone in the presence of high salt intake in the diet induces LVH and fibrosis. ${ }^{63,64}$

Experimental studies and recent studies in humans ${ }^{65,66}$ support the occurrence of clinically relevant and bidirectional interactions between aldosterone and parathyroid hormone (PTH), with potential impact on the cardiovascular system. There is evidence that PTH increases the adrenal aldosterone secretion directly and indirectly by activating the RAAS. This stimulation of PTH hormones in the RAAS may potentiate risks in the development and progression of HTN as well as increase the risk of cardiovascular disease in patients with primary hyperparathyroidism..$^{54,67-69}$

\section{Obstructive sleep-apnea syndrome (OSAS), autonomic dysfunction, and obesity}

Goodfriend and Calhoun ${ }^{70}$ demonstrated an association between OSAS and aldosteronism in RHTN. Several mechanisms are involved in the pathophysiology of RHTN associated with OSAS, in particular hyperactivity of the sympathetic nervous system, manifested in excitement of chemoreceptors and dysfunction of baroreceptors leading to high BP. ${ }^{71}$ Excessive aldosterone seems to contribute to OSAS by mechanisms involving fluid retention and edema of the nasopharynx, with consequent obstruction of the upper airways..$^{71,72}$ Obesity also seems independently to stimulate the autonomic nervous system and thus contribute to the lack of BP control in RHTN individuals (Figure 1).

\section{Aldosterone receptors, aldosterone synthase, and polymorphisms}

The effects of aldosterone are mediated through its binding to $\mathrm{MRs},{ }^{73}$ which promotes extracellular volume retention by a genomic pathway and endothelial dysfunction, inflammation, and oxidative stress, among other cardiovascular and renal structural and functional abnormalities by nongenomic actions. ${ }^{74}$ In addition to this, obesity - through the release of select adipokines ${ }^{75}$ - and overactivity of the sympathetic nervous system may stimulate aldoste-

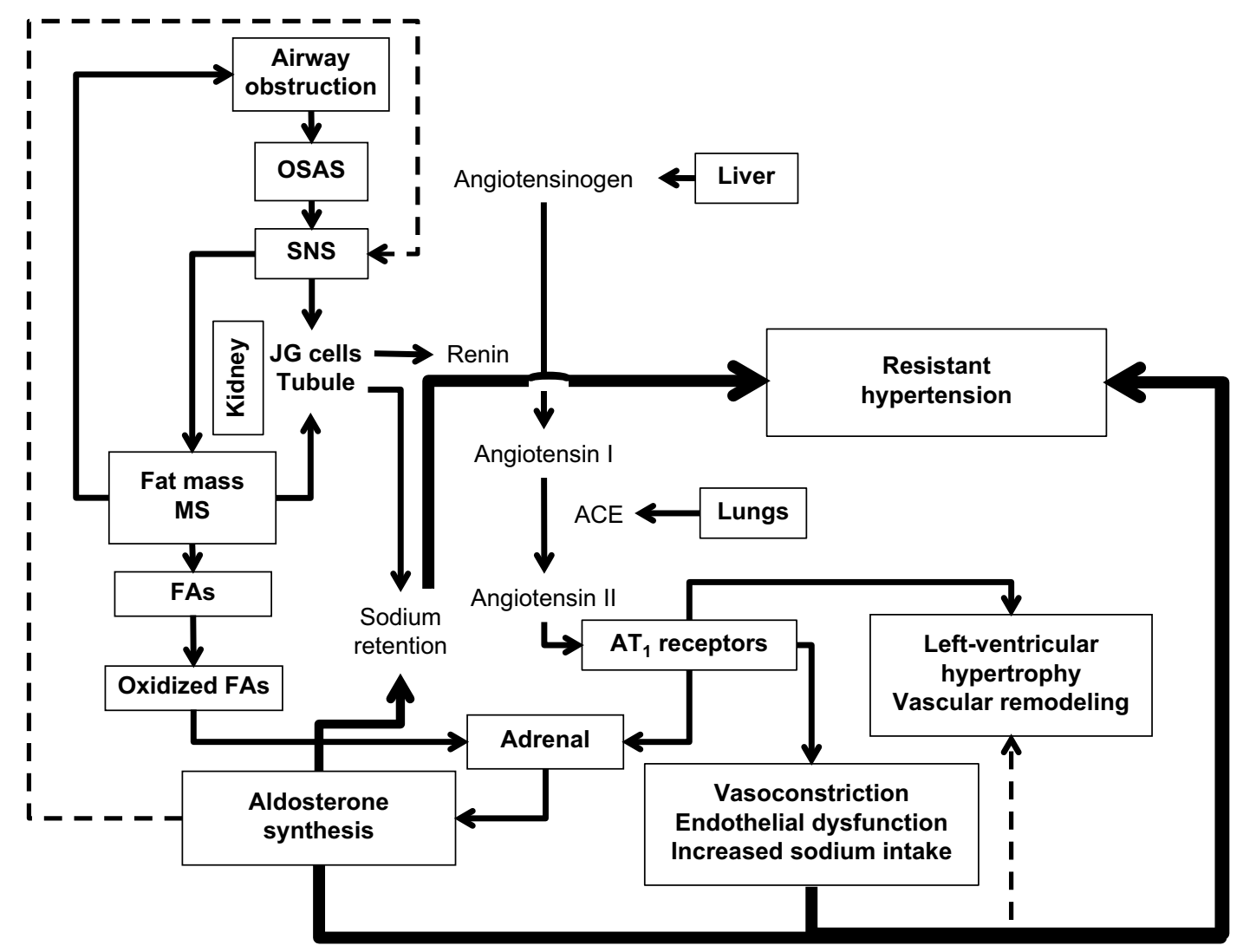

Figure I Relationships among factors in resistant hypertension.

Notes: Increased aldosterone secretion increases activation of the SNS. Intravascular volume control is obtained by directly influencing electrolyte balance via changes in endothelial permeability and inhibition of sodium reabsorption in proximal and distal nephrons and increased SNS activity. Solid lines indicate principal pathways; dotted lines indicate secondary pathways. Data from Goodfriend and Calhoun. ${ }^{70}$

Abbreviations: SNS, sympathetic nervous system; OSAS, obstructive sleep-apnea syndrome; JG, juxtaglomerular; MS, metabolic syndrome; FAs, fatty acids. 
rone secretion. ${ }^{70}$ In this context, and due to the complex condition of RHTN and its associated comorbidities, it is important to remember that aldosterone, with its elevated levels mediating several maladaptive changes, seems to be a complicating factor in subjects resistant to antihypertensive therapy.

Due to its multifactorial condition, HTN may be influenced by a genetic factor, which may also explain the current interindividual variability in plasma aldosterone levels. Aldosterone synthase (CYP11B2) is an interesting target that catalyzes the final step of aldosterone synthesis in the adrenal cortex. The differences in aldosterone biosynthesis between individuals may be attributed to genetic polymorphisms of the CYP11B2 gene, as demonstrated by the communitybased Framingham Heart Study. ${ }^{76}$ Indeed, the $-344 \mathrm{C} / \mathrm{T}$ polymorphism has been widely investigated in cardiovascular conditions. Recently, a cross-sectional study including RHTN subjects revealed that individuals with the TT polymorphism presented higher plasma aldosterone concentrations than those with the CT and CC polymorphisms, even with the use of spironolactone. ${ }^{77}$ A meta-analysis demonstrated that homozygous individuals (CC) for this polymorphism were at $17 \%$ lower risk of HTN compared to TT subjects. ${ }^{78}$ The presence of the $\mathrm{T}$ allele was also associated with higher $\mathrm{BP}^{79}$ and urinary aldosterone excretion. ${ }^{80}$ Furthermore, genetic polymorphisms of the MR gene $(N C 3 C 2)$ have also been explored. Ritter et al showed that subjects with RHTN carrying the $\mathrm{G}$ allele for the $1180 \mathrm{~V}$ polymorphism presented higher aldosterone levels, systolic ambulatory BP, and LVH, despite a higher proportion of ACE inhibitors and $\beta$-blocker use than homozygous AA individuals. Even with its cross-sectional design, this study suggests that this genetic variation might be a risk factor for resistance to antihypertensive therapy. ${ }^{81}$

Finally, aldosterone function has been extensively discussed in recent years as a key piece in RHTN. Therefore, the addition of MRA to the usual antihypertensive treatment in this hard-to-treat condition is of great clinical importance, since it may provide additional and pronounced BP reductions. ${ }^{82,83}$

\section{Spironolactone}

\section{Pharmacological aspects}

MRAs being indicated for the treatment of RHTN is based on studies that have shown effectiveness, safety, and cardiovascular and renal protection. ${ }^{82,84-88}$ Spironolactone is an unselective MRA that has a complex metabolism and a half-life exceeding 12 hours in healthy individuals, 24 hours in patients with heart failure, and up to 58 hours in cirrhotic patients with ascites. The most common side effects observed with spironolactone - gynecomastia, breast pains, erectile dysfunction, and menstrual irregularities - result from the binding of the drug to the androgen receptor, preventing its interaction with dihydrotestosterone. The incidence of these adverse effects is not high (approximately 2\%-9\% of patients) and reversible after discontinuation of treatment. ${ }^{82,85}$

\section{Spironolactone in RHTN}

In 2003, Nishizaka et a ${ }^{89}$ highlighted the importance of adding a low dose of spironolactone to the therapeutic scheme of patients with RHTN, with the aim of obtaining an additional reduction in BP in both black and Caucasian populations, regardless of ARR. Sartori et $\mathrm{al}^{90}$ conducted the first prospective study involving difficult-to-control hypertensive patients with high ARR, and showed the importance of this ratio in the pathophysiology of RHTN, even in the absence of clinical manifestations, thus reinforcing the inclusion of aldosterone antagonists in the therapy of these patients. Lane et $\mathrm{al}^{91}$ evaluated resistant hypertensive patients, adding spironolactone (25-50 mg/day) to standard triple therapy. These authors observed an additional antihypertensive effect in this group of subjects, suggesting that the addition of spironolactone may be useful, even in the absence of an elevated ARR in RHTN. Other studies ${ }^{84,92-95}$ substantiated the importance of the addition of spironolactone in antihypertensive therapy of RHTN patients. However, the high incidence of gynecomastia and breast pain among patients taking this drug was significant.

\section{Eplerenone}

A multicenter, double-blinded, placebo-controlled trial demonstrated that eplerenone was effective in reducing BP in subjects with mild-moderate HTN compared to a placebo. In addition, no clinically relevant safety issues were observed in eplerenone-treated subjects. ${ }^{96}$ Selective aldosterone blockade with eplerenone was also useful as an add-on therapy in hypertensive patients who were inadequately controlled on either ACE inhibitors or ARBs alone. ${ }^{97}$ Either alone or in combination with enalapril, eplerenone also proved to be effective in regression of target-organ damage, such as $\mathrm{LVH}$ in hypertensive subjects ${ }^{98}$ and albuminuria in type 2 diabetic patients, ${ }^{99}$ but was found to be even better when combined with an ACE inhibitor. Moreover, eplerenone reduces arterial stiffness, the collagen:elastin ratio, and circulating inflammatory mediators. ${ }^{100}$ All these findings in HTN favor the use of eplerenone as the fourth drug to treat RHTN.

The selective aldosterone antagonist eplerenone has also been explored in RHTN. This drug proved to be effective and 
well tolerated, with modest changes in serum potassium in this high-risk population. At the end of a 12-week activetreatment period added to the complex medication regimen of RHTN subjects, the change from baseline in 24-hour mean BP was $-12.2 /-6 \mathrm{mmHg}(P<0.0001) .{ }^{82}$ Moreover, the addition of eplerenone enabled $39 \%$ of patients to achieve 24-hour average ambulatory BP levels $<135 / 85 \mathrm{mmHg}$ and a $63.5 \%$ success rate in achieving office systolic BP $<140$ $\mathrm{mmHg}$. Despite this, aldosterone and renin activity could not predict BP responses to eplerenone in this study population. ${ }^{82}$ In addition, a randomized, open-label, parallel-controlled trial demonstrated that endothelial function - assessed by flowmediated vasodilation - improved after 12 weeks of eplerenone, which seems to be a BP-independent effect. ${ }^{101}$ Taken together, these findings suggest that eplerenone treatment not only reduces BP levels but also limits end-organ damage.

\section{The use of aldosterone antagonists in RHTN: current insights and perspectives}

Currently, MRAs are not indicated to be used as first-, second-, or even third-line drugs in RHTN. On the other hand, due to the high prevalence of PA in RHTN, studies have shown relevant antihypertensive benefits of adding an MRA to the existing multidrug regimen..$^{85,102}$ Williams et al ${ }^{83}$ performed the first randomized controlled trial (the PATHWAY-2 study) comparing different antihypertensive treatments in a rigorous assessment of subjects with RHTN. In this study, spironolactone (25-50 mg/day) was clearly considered the most effective drug added to the three recommended drugs an ACE inhibitor/angiotensin II-receptor blocker, plus a calcium-channel blocker, plus a thiazide-like diuretic - in the treatment of RHTN. ${ }^{49}$ This trial is considered a milestone, since it overcame the limitations of previous observational and interventional studies, mainly because PATHWAY-2 was designed to use active comparators (widely used antihypertensive drugs), instead of just a placebo. ${ }^{103}$ Moreover, a recent systematic review and meta-analysis has supported it by comparing MRAs with other fourth-line antihypertensive agents in patients with RHTN. MRAs reduced BP more effectively than the other fourth-line agents in randomized and nonrandomized studies. ${ }^{104}$

It is well known that the effect of MRAs on BP reduction includes renal and extrarenal pathways. Treatment with MRAs has been shown to attenuate end-organ damage, mainly because of prevention of nongenomic effects of aldosterone, which lead to increased arterial stiffness and oxidative stress. For instance, reduced cardiac hypertrophy was seen at 3- and 6-month follow-ups in RHTN subjects (with or without PA) taking spironolactone (added to the ongoing antihypertensive regimen at $25 \mathrm{mg}$ /day and forcetitrated to $50 \mathrm{mg}$ /day at 4 weeks). ${ }^{105}$ The BP-lowering effect and BP-independent effect contribute to place MRAs as very attractive drugs to treat the complex and multifactorial condition of RHTN (Figure 2).

The most concerning adverse effect of MRA treatment is hyperkalemia. ${ }^{106,107}$ Therefore, periodic monitoring of serum potassium and renal function are mandatory, especially in patients at high risk of developing this disorder (elderly patients with renal impairment or diabetes). ${ }^{108}$ Taking concurrent pharmacotherapies associated with hyperkalemia, such as potassium supplements, other potassium-sparing diuretics, and nonsteroidal anti-inflammatory drugs, should be avoided. Furthermore, the concomitant use of an MRA with ACE inhibitors or ARBs requires special attention. ${ }^{109,110}$ Because of this, experts have recommended MRAs for subjects with RHTN only with careful monitoring of serum potassium levels. Finally, it has been demonstrated that the combined use of spironolactone with a thiazide diuretic, such as chlorthalidone, at optimal doses not only provides greater efficacy but also reduces the risk of spironolactone-induced hyperkalemia. ${ }^{11}$

Eplerenone in the treatment of RHTN still lacks data, but substantial efficacy and good tolerability have been demonstrated with modest changes in plasma potassium. ${ }^{82}$ The most recently developed MRA, finerenone, has not been studied in RHTN, although its pharmacokinetic profile is promising. ${ }^{112}$ Other agents similarly affecting aldosterone effects may be alternatives in patients with RHTN. A recent highly selective and potent aldosterone-synthase inhibitor - RO6836191 - has the potential of being used in the clinical setting. ${ }^{113}$ Another aldosterone-synthase inhibitor - CYP11B2 (LC1699) reduces both office and $\mathrm{ABPM}$ pressures in $\mathrm{PA}$, but its development was discontinued because of cortisol response to adrenocorticotropic hormone stimulation was significantly suppressed in $20 \%$ of patients. ${ }^{114}$ These findings suggest that new compounds will be identified for future use to treat RHTN. ${ }^{115}$ Finally, thiazolidinedione agonists, which act on PPAR $\gamma$ receptors and are widely used in the treatment of type 2 diabetes, in addition to their known antiproliferative effects, can also suppress aldosterone production. ${ }^{116}$ Therefore, they may potentially be useful in combination with conventional antihypertensive therapy for patients with RHTN who also have insulin resistance and type 2 diabetes. 

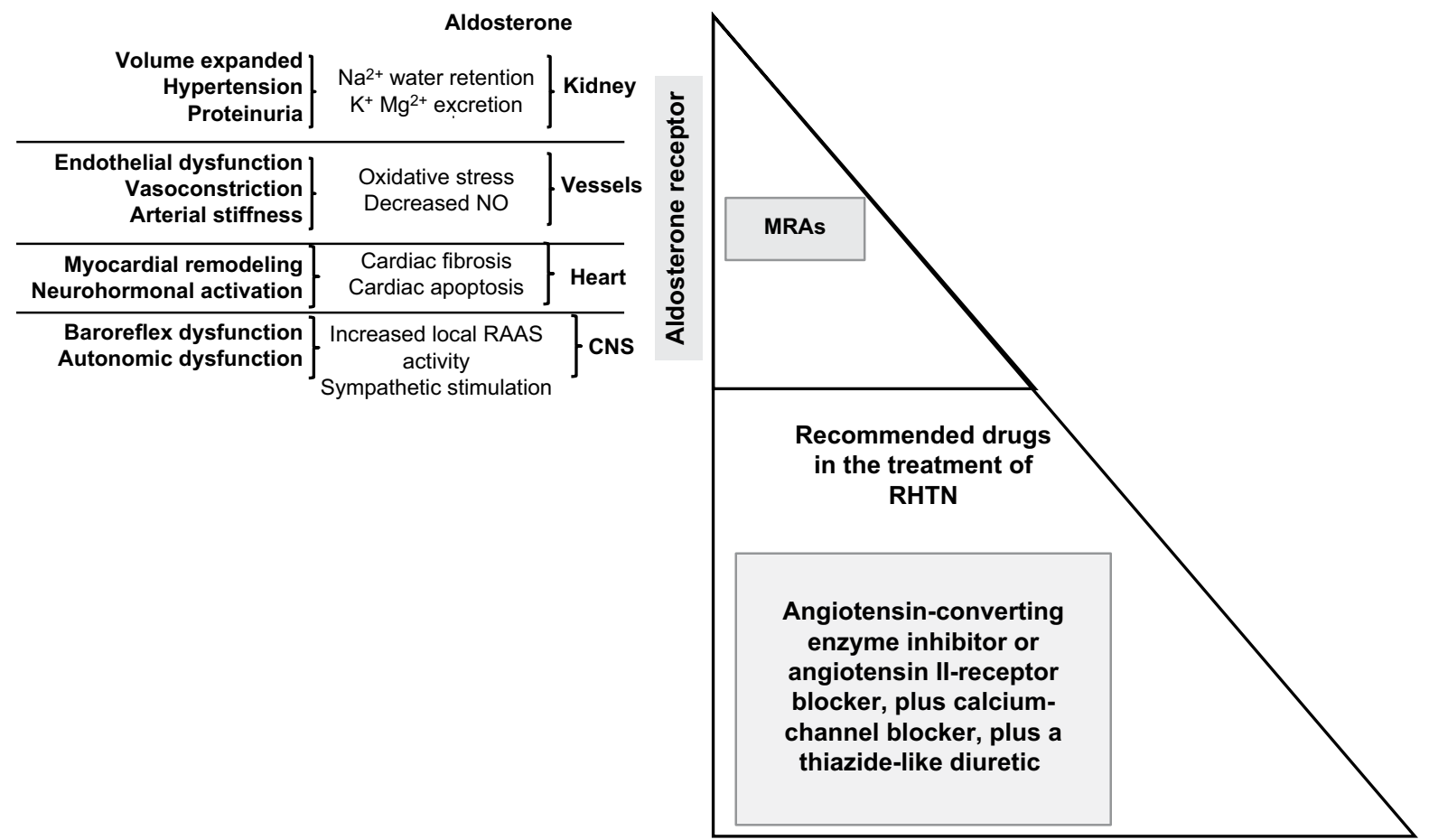

Figure 2 Fourth-line antihypertensive agents in patients with RHTN.

Notes: MRAs compete for the binding sites of aldosterone, effectively decrease blood pressure, and attenuate end-organ damage, mainly because of preventing nongenomic effects of aldosterone, which lead to arterial stiffness and increased oxidative stress.

Abbreviations: RHTN, resistant hypertension; MRAs, mineralocorticoid-receptor agonists; RAAS, renin-angiotensin-aldosterone system; CNS, central nervous system.

In conclusion, based on the many lines of evidence, such MRAs as spironolactone should be considered the fourthline drug in the treatment of RHTN. ${ }^{104,117-119}$ Unfortunately, a retrospective cohort study, which examined antihypertensivemedication trends from the introduction of the 2008 American Heart Association Scientific statement on RHTN to December 2014, highlighted the persistent infrequent use of recommended therapies, including spironolactone, in RHTN subjects. Spironolactone use increased by about $38 \%$ from 2008 to 2014, although with low overall prevalence: it was used in only one in ten cases of RHTN. ${ }^{120}$ With the recent evidence, greater efforts are needed to increase the use of recommended antihypertensive drugs, including such MRAs as spironolactone, among patients with RHTN.

\section{Disclosure}

The authors report no conflicts of interest in this work.

\section{References}

1. Conn JW. Primary aldosteronism. J Lab Clin Med. 1955;45(4):661-664.

2. Gordon RD, Fishman LM, Liddle GW. Plasma renin activity and aldosterone secretion in a pregnant woman with primary aldosteronism. J Clin Endocrinol Metab. 1967;27(3):385-388.

3. Fishman LM, Küchel O, Liddle GW, Michelakis AM, Gordon RD, Chick WT. Incidence of primary aldosteronism uncomplicated "essential" hypertension: a prospective study with elevated aldosterone secretion and suppressed plasma renin activity used as diagnostic criteria. JAMA. 1968;205(7):497-502.
4. Marsen B, Dissmann T, Oelkers W, Lohmann FW, Molzahn M, Gotzen R. [Endocrinologic and circulatory findings in a case of primary aldosteronism]. Dtsch Med Wochenschr. 1971;96(22):951-954. German.

5. Rossi CA, Echeverria H. [Primary aldosteronism]. Prensa Med Argent. 1971;57(15):777-782. Spanish.

6. Laragh JH. Hormonal profiling in the diagnosis and treatment of essential hypertension. Del Med J. 1974;46(3):125-133.

7. McCaa CS, Langford HG, Cushman WC, McCaa RE. Response of arterial blood pressure, plasma renin activity and plasma aldosterone concentration to long-term administration of captopril in patients with severe, treatment-resistant malignant hypertension. Clin Sci (Lond). 1979;57(Suppl 5):371s-373s.

8. Laragh JH, Letcher RL, Pickering TG. Renin profiling for diagnosis and treatment of hypertension. JAMA. 1979;241(2):151-156.

9. Lim RC Jr, Nakayama DK, Biglieri EG, Schambelan M, Hunt TK. Primary aldosteronism: changing concepts in diagnosis and management. Am J Surg. 1986;152(1):116-121.

10. Griffing GT, Wilson TE, Melby JC. Alterations in aldosterone secretion and metabolism in low renin hypertension. J Clin Endocrinol Metab. 1990;71(6):1454-1460.

11. Gordon RD, Stowasser M, Tunny TJ, Klemm SA, Finn WL, Krek AL. Clinical and pathological diversity of primary aldosteronism, including a new familial variety. Clin Exp Pharmacol Physiol. 1991;18(5): 283-286.

12. Gordon RD, Stowasser M, Tunny TJ, Klemm SA, Rutherford JC. High incidence of primary aldosteronism in 199 patients referred with hypertension. Clin Exp Pharmacol Physiol. 1994;21(4):315-318.

13. Lim PO, Young WF, MacDonald TM. A review of the medical treatment of primary aldosteronism. J Hypertens. 2001;19(3):353-361.

14. Lim PO, MacDonald TM. Primary aldosteronism, diagnosed by the aldosterone to renin ratio, is a common cause of hypertension. Clin Endocrinol (Oxf). 2003;59(4):427-430.

15. Conn JW, Cohen EL, Rovner DR, Nesbit RM. Normokalemic primary aldosteronism: a detectable cause of curable "essential" hypertension. JAMA. 1965;193(3):200-206. 
16. Pessina AC, Sacchetto A, Rossi GP. Left ventricular anatomy and function in primary aldosteronism and renovascular hypertension. In: Zanchetti A, Devereux RB, Hansson L, Gorini S, editors. Hypertension and the Heart. Heidelberg: Springer; 1997:63-69.

17. Mackenzie SM, Connell J. Hypertension and the expanding role of aldosterone. Curr Hypertens Rep. 2006;8(3):255-261.

18. Duprez DA, Bauwens FR, De Buyzere ML, et al. Influence of arterial blood pressure and aldosterone on left ventricular hypertrophy in moderate essential hypertension. Am J Cardiol. 1993;71(3):17A-20A.

19. Blacher J,Amah G, Girerd X, et al. Association between increased plasma levels of aldosterone and decreased systemic arterial compliance in subjects with essential hypertension. Am J Hypertens. 1997;10(12 Pt 1): 1326-1334.

20. Rocha R, Stier CT Jr, Kifor I, et al. Aldosterone: a mediator of myocardial necrosis and renal arteriopathy. Endocrinology. 2000;141(10):3871-3878.

21. El-Gharbawy AH, Nadig VS, Kotchen JM, et al. Arterial pressure, left ventricular mass, and aldosterone in essential hypertension. Hypertension. 2001;37(3):845-850.

22. Rocha R, Funder JW. The pathophysiology of aldosterone in the cardiovascular system. Ann N Y Acad Sci. 2002;970:89-100.

23. Blasi ER, Rocha R, Rudolph AE, Blomme EA, Polly ML, McMahon EG. Aldosterone/salt induces renal inflammation and fibrosis in hypertensive rats. Kidney Int. 2003;63(5):1791-1800.

24. Rossi GP, Cesari M, Pessina AC. Left ventricular changes in primary aldosteronism. Am J Hypertens. 2003;16(1):96-98.

25. Dartsch T, Fischer R, Gapelyuk A, et al. Aldosterone induces electrical remodeling independent of hypertension. Int J Cardiol. 2013;164(2):170-178.

26. Rossi GP, Seccia TM, Gallina V, et al. Prospective appraisal of the prevalence of primary aldosteronism in hypertensive patients presenting with atrial flutter or fibrillation (PAPPHY study): rationale and study design. J Hum Hypertens. 2013;27(3):158-163.

27. Rossi GP, Bolognesi M, Rizzoni D, et al. Vascular remodeling and duration of hypertension predict outcome of adrenalectomy in primary aldosteronism patients. Hypertension. 2008;51(5):1366-1371.

28. Martinez-Aguayo A, Carvajal CA, Campino C, et al. Primary aldosteronism and its impact on the generation of arterial hypertension, endothelial injury and oxidative stress. J Pediatr Endocrinol Metab. 2010;23(4):323-330.

29. Farquharson CA, Struthers AD. Spironolactone increases nitric oxide bioactivity, improves endothelial vasodilator dysfunction, and suppresses vascular angiotensin I/angiotensin II conversion in patients with chronic heart failure. Circulation. 2000;101(6):594-597.

30. Rocha R, Stier CT Jr. Pathophysiological effects of aldosterone in cardiovascular tissues. Trends Endocrinol Metab. 2001;12(7):308-314.

31. Rocha R, Rudolph AE, Frierdich GE, et al. Aldosterone induces a vascular inflammatory phenotype in the rat heart. Am J Physiol Heart Circ Physiol. 2002;283(5):H1802-H1810.

32. Takeda Y. Role of cardiovascular aldosterone in hypertension. Curr Med Chem Cardiovasc Hematol Agents. 2005;3(3):261-266.

33. Yugar-Toledo JC, Bonalume-Tacito LH, Ferreira-Melo SE, et al. Lowrenin (volume dependent) mild-hypertensive patients have impaired flow-mediated and glyceryl-trinitrate stimulated vascular reactivity. Circ J. 2005;69(11):1380-1385.

34. Schiffrin EL. Effects of aldosterone on the vasculature. Hypertension. 2006;47(3):312-318.

35. Ruilope LM. Aldosterone, hypertension, and cardiovascular disease: an endless story. Hypertension. 2008;52(2):207-208.

36. Calhoun DA, Nishizaka MK, Zaman MA, Thakkar RB, Weissmann P. Hyperaldosteronism among black and white subjects with resistant hypertension. Hypertension. 2002;40(6):892-896.

37. Gallay BJ, Ahmad S, Xu L, Toivola B, Davidson RC. Screening for primary aldosteronism without discontinuing hypertensive medications: plasma aldosterone-renin ratio. Am J Kidney Dis. 2001;37(4): 699-705.
38. Strauch B, Zelinka T, Hampf M, Bernhardt R, Widimsky J Jr. Prevalence of primary hyperaldosteronism in moderate to severe hypertension in the Central Europe region. J Hum Hypertens. 2003;17(5): 349-352.

39. Eide IK, Torjesen PA, Drolsum A, Babovic A, Lilledahl NP. Low-renin status in therapy-resistant hypertension: a clue to efficient treatment. J Hypertens. 2004;22(11):2217-2226.

40. Kayser SC, Dekkers T, Groenewoud HJ, et al. Study heterogeneity and estimation of prevalence of primary aldosteronism: a systematic review and meta-regression analysis. J Clin Endocrinol Metab. 2016;101(7):2826-2835.

41. Calhoun DA, Jones D, Textor S, et al. Resistant hypertension: diagnosis, evaluation, and treatment: a scientific statement from the American Heart Association Professional Education Committee of the Council for High Blood Pressure Research. Circulation. 2008;117(25):e510-e526.

42. Pimenta E, Gaddam KK, Pratt-Ubunama MN, et al. Aldosterone excess and resistance to 24-h blood pressure control. J Hypertens. 2007;25(10):2131-2137.

43. Siddiqui M, Calhoun DA. Refractory versus resistant hypertension. Curr Opin Nephrol Hypertens. 2017;26(1):14-19.

44. Martins LC, Figueiredo VN, Quinaglia T, et al. Characteristics of resistant hypertension: ageing, body mass index, hyperaldosteronism, cardiac hypertrophy and vascular stiffness. J Hum Hypertens. 2011;25(9):532-538.

45. de Faria AP, Demacq C, Figueiredo VN, et al. Hypoadiponectinemia and aldosterone excess are associated with lack of blood pressure control in subjects with resistant hypertension. Hypertens Res. 2013;36(12):1067-1072.

46. Sabbatini AR, Faria AP, Barbaro NR, et al. Deregulation of adipokines related to target organ damage on resistant hypertension. J Hum Hypertens. 2014;28(6):388-392.

47. Menon DV, Arbique D, Wang Z, Adams-Huet B, Auchus RJ, Vongpatanasin W. Differential effects of chlorthalidone versus spironolactone on muscle sympathetic nerve activity in hypertensive patients. J Clin Endocrinol Metab. 2009;94(4):1361-1366.

48. Modolo R, de Faria AP, Almeida A, Moreno H. Resistant or refractory hypertension: are they different? Curr Hypertens Rep. 2014;16(10): 485.

49. Acelajado MC, Pisoni R, Dudenbostel T, et al. Refractory hypertension: definition, prevalence, and patient characteristics. J Clin Hypertens (Greenwich). 2012;14(1):7-12.

50. Brambilla G, Bombelli M, Seravalle G, et al. Prevalence and clinical characteristics of patients with true resistant hypertension in central and Eastern Europe: data from the BP-CARE study. J Hypertens. 2013;31(10):2018-2024

51. Staessen J, Lijnen P, Fagard R, Verschueren LJ, Amery A. Rise in plasma concentration of aldosterone during long-term angiotensin II suppression. J Endocrinol. 1981;91(3):457-465.

52. Ubaid-Girioli S, de Souza LA, Yugar-Toledo JC, et al. Aldosterone excess or escape: treating resistant hypertension. $J$ Clin Hypertens (Greenwich). 2009;11(5):245-252.

53. Schjoedt KJ, Andersen S, Rossing P, Tarnow L, Parving HH. Aldosterone escape during blockade of the renin-angiotensin-aldosterone system in diabetic nephropathy is associated with enhanced decline in glomerular filtration rate. Diabetologia. 2004;47(11):1936-1939.

54. Tomaschitz A, Ritz E, Pieske B, et al. Aldosterone and parathyroid hormone interactions as mediators of metabolic and cardiovascular disease. Metabolism. 2014;63(1):20-31.

55. Gaddam KK, Nishizaka MK, Pratt-Ubunama MN, et al. Characterization of resistant hypertension: association between resistant hypertension, aldosterone, and persistent intravascular volume expansion. Arch Intern Med. 2008;168(11):1159-1164.

56. Taler SJ, Textor SC, Augustine JE. Resistant hypertension: comparing hemodynamic management to specialist care. Hypertension. 2002;39(5):982-988. 
57. Rossi GP, Sacchetto A, Visentin P, et al. Changes in left ventricular anatomy and function in hypertension and primary aldosteronism. Hypertension. 1996;27(5):1039-1045.

58. Nishimura M, Uzu T, Fujii T, et al. Cardiovascular complications in patients with primary aldosteronism. Am J Kidney Dis. 1999;33(2): 261-266.

59. Schlaich MP, Schobel HP, Hilgers K, Schmieder RE. Impact of aldosterone on left ventricular structure and function in young normotensive and mildly hypertensive subjects. Am J Cardiol. 2000;85(10):1199-1206.

60. Matsumura K, Fujii K, Oniki H, Oka M, Iida M. Role of aldosterone in left ventricular hypertrophy in hypertension. Am J Hypertens. 2006;19(1):13-18.

61. Catena C, Colussi G, Nadalini E, et al. Cardiovascular outcomes in patients with primary aldosteronism after treatment. Arch Intern Med. 2008;168(1):80-85.

62. Catena C, Colussi G, Marzano L, Sechi LA. Aldosterone and the heart: from basic research to clinical evidence. Horm Metab Res. 2012;44(3):181-187.

63. Brilla CG, Weber KT. Mineralocorticoid excess, dietary sodium, and myocardial fibrosis. J Lab Clin Med. 1992;120(6):893-901.

64. Young M, Head G, Funder J. Determinants of cardiac fibrosis in experimental hypermineralocorticoid states. Am J Physiol. 1995; 269(4 Pt 1):E657-E662.

65. Chhokar VS, Sun Y, Bhattacharya SK, et al. Hyperparathyroidism and the calcium paradox of aldosteronism. Circulation. 2005;111(7):871-878.

66. Law PH, Sun Y, Bhattacharya SK, Chhokar VS, Weber KT. Diuretics and bone loss in rats with aldosteronism. J Am Coll Cardiol. 2005;46(1): 142-146.

67. Maniero C, Fassina A, Seccia TM, et al. Mild hyperparathyroidism: a novel surgically correctable feature of primary aldosteronism. J Hypertens. 2012;30(2):390-395.

68. Tomaschitz A, Ritz E, Pieske B, et al. Aldosterone and parathyroid hormone: a precarious couple for cardiovascular disease. Cardiovasc Res. 2012;94(1):10-19.

69. Zhang Y, Feng B. Association of serum parathyrine and calcium levels with primary aldosteronism: a meta-analysis. Int J Clin Exp Med. 2015;8(9):14625-14633.

70. Goodfriend TL, Calhoun DA. Resistant hypertension, obesity, sleep apnea, and aldosterone: theory and therapy. Hypertension. 2004;43(3): 518-524.

71. Pack AI, Gislason T. Obstructive sleep apnea and cardiovascular disease: a perspective and future directions. Prog Cardiovasc Dis. 2009;51(5):434-451.

72. Gonzaga CC, Gaddam KK, Ahmed MI, et al. Severity of obstructive sleep apnea is related to aldosterone status in subjects with resistant hypertension. J Clin Sleep Med. 2010;6(4):363-368.

73. Wehling M. Effects of aldosterone and mineralocorticoid receptor blockade on intracellular electrolytes. Heart Fail Rev. 2005;10(1): 39-46.

74. Sowers JR, Whaley-Connell A, Epstein M. Narrative review: the emerging clinical implications of the role of aldosterone in the metabolic syndrome and resistant hypertension. Ann Intern Med. 2009;150(11):776-783.

75. Ehrhart-Bornstein M, Lamounier-Zepter V, Schraven A, et al. Human adipocytes secrete mineralocorticoid-releasing factors. Proc Natl Acad Sci USA. 2003;100(24):14211-14216.

76. Kathiresan S, Larson MG, Benjamin EJ, et al. Clinical and genetic correlates of serum aldosterone in the community: the Framingham Heart Study. Am J Hypertens. 2005;18(5 Pt 1):657-665.

77. Fontana V, de Faria AP, Barbaro NR, et al. Modulation of aldosterone levels by $-344 \mathrm{C} / \mathrm{T}$ CYP11B2 polymorphism and spironolactone use in resistant hypertension. J Am Soc Hypertens. 2014;8(3):146-151.

78. Sookoian S, Gianotti TF, Gonzalez CD, Pirola CJ. Association of the $\mathrm{C}$-344T aldosterone synthase gene variant with essential hypertension: a meta-analysis. J Hypertens. 2007;25(1):5-13.
79. Takeuchi F, Yamamoto K, Katsuya T, et al. Reevaluation of the association of seven candidate genes with blood pressure and hypertension: a replication study and meta-analysis with a larger sample size. Hypertens Res. 2012;35(8):825-831.

80. Davies E, Holloway CD, Ingram MC, et al. Aldosterone excretion rate and blood pressure in essential hypertension are related to polymorphic differences in the aldosterone synthase gene CYP11B2. Hypertension. 1999;33(2):703-707.

81. Ritter AM, Fontana V, Faria AP, et al. Association of mineralocorticoid receptor polymorphism $1180 \mathrm{~V}$ with left ventricular hypertrophy in resistant hypertension. Am J Hypertens. 2016;29(2):245-250.

82. Calhoun DA, White WB. Effectiveness of the selective aldosterone blocker, eplerenone, in patients with resistant hypertension. J Am Soc Hypertens. 2008;2(6):462-468.

83. Williams B, MacDonald TM, Morant S, et al. Spironolactone versus placebo, bisoprolol, and doxazosin to determine the optimal treatment for drug-resistant hypertension (PATHWAY-2): a randomised, doubleblind, crossover trial. Lancet. 2015;386(10008):2059-2068.

84. Calhoun DA. Low-dose aldosterone blockade as a new treatment paradigm for controlling resistant hypertension. J Clin Hypertens (Greenwich). 2007;9(1 Suppl 1):19-24.

85. Chapman N, Dobson J, Wilson S, et al. Effect of spironolactone on blood pressure in subjects with resistant hypertension. Hypertension. 2007;49(4):839-845.

86. Pimenta E, Calhoun DA. Treatment of resistant hypertension. J Hypertens. 2010;28(11):2194-2195.

87. Colussi G, Catena C, Sechi LA. Spironolactone, eplerenone and the new aldosterone blockers in endocrine and primary hypertension. J Hypertens. 2013;31(1):3-15.

88. Catena C, Colussi G, Sechi LA. Mineralocorticoid receptor antagonists and renal involvement in primary aldosteronism: opening of a new era. Eur J Endocrinol. 2013;168(1):C1-C5.

89. Nishizaka MK, Zaman MA, Calhoun DA. Efficacy of low-dose spironolactone in subjects with resistant hypertension. Am J Hypertens. 2003;16(11 Pt 1):925-930.

90. Sartori M, Calo LA, Mascagna V, et al. Aldosterone and refractory hypertension: a prospective cohort study. Am J Hypertens. 2006;19(4): 373-380.

91. Lane DA, Shah S, Beevers DG. Low-dose spironolactone in the management of resistant hypertension: a surveillance study. J Hypertens. 2007;25(4):891-894.

92. Gaddam KK, Pratt-Ubunama MN, Calhoun DA. Aldosterone antagonists: effective add-on therapy for the treatment of resistant hypertension. Expert Rev Cardiovasc Ther. 2006;4(3):353-359.

93. Pimenta E, Calhoun DA. Resistant hypertension and aldosteronism. Curr Hypertens Rep. 2007;9(5):353-359.

94. Jansen PM, Danser AH, Imholz BP, van den Meiracker AH. Aldosterone-receptor antagonism in hypertension. J Hypertens. 2009;27(4):680-691.

95. Das G, De P. Aldosterone renin ratio in patients with resistant hypertension. QJM. 2010;103(11):897-899.

96. Weinberger MH, Roniker B, Krause SL, Weiss RJ. Eplerenone, a selective aldosterone blocker, in mild-to-moderate hypertension. Am J Hypertens. 2002;15(8):709-716.

97. Krum H, Nolly H, Workman D, et al. Efficacy of eplerenone added to renin-angiotensin blockade in hypertensive patients. Hypertension. 2002;40(2):117-123.

98. Pitt B, Reichek N, Willenbrock R, et al. Effects of eplerenone, enalapril, and eplerenone/enalapril in patients with essential hypertension and left ventricular hypertrophy: the 4E-left ventricular hypertrophy study. Circulation. 2003;108(15):1831-1838.

99. Epstein M, Williams GH, Weinberger M, et al. Selective aldosterone blockade with eplerenone reduces albuminuria in patients with type 2 diabetes. Clin J Am Soc Nephrol. 2006;1(5):940-951.

100. Savoia C, Touyz RM, Amiri F, Schiffrin EL. Selective mineralocorticoid receptor blocker eplerenone reduces resistance artery stiffness in hypertensive patients. Hypertension. 2008;51(2):432-439. 
101. Eguchi K, Kabutoya T, Hoshide S, Ishikawa S, Kario K. Add-on use of eplerenone is effective for lowering home and ambulatory blood pressure in drug-resistant hypertension. J Clin Hypertens (Greenwich). 2016;18(12):1250-1257.

102. Ouzan J, Perault C, Lincoff AM, Carre E, Mertes M. The role of spironolactone in the treatment of patients with refractory hypertension. Am J Hypertens. 2002;15(4 Pt 1):333-339.

103. Narayan H, Webb DJ. New evidence supporting the use of mineralocorticoid receptor blockers in drug-resistant hypertension. Curr Hypertens Rep. 2016;18(5):34.

104. Sinnott SJ, Tomlinson LA, Root AA, et al. Comparative effectiveness of fourth-line anti-hypertensive agents in resistant hypertension: a systematic review and meta-analysis. Eur J Prev Cardiol. 2017;24(3):228-238.

105. Gaddam K, Corros C, Pimenta E, et al. Rapid reversal of left ventricular hypertrophy and intracardiac volume overload in patients with resistant hypertension and hyperaldosteronism: a prospective clinical study. Hypertension. 2010;55(5):1137-1142.

106. Witham MD, Gillespie ND, Struthers AD. Hyperkalemia after the publication of RALES. N Engl J Med. 2004;351(23):2448-2450.

107. Juurlink DN, Mamdani MM, Lee DS, et al. Rates of hyperkalemia after publication of the Randomized Aldactone Evaluation Study. N Engl J Med. 2004;351(6):543-551.

108. McMurray JJ, Adamopoulos S, Anker SD, et al. ESC guidelines for the diagnosis and treatment of acute and chronic heart failure 2012. Eur J Heart Fail. 2012;14(8):803-869.

109. Pitt B, Bakris G, Ruilope LM, DiCarlo L, Mukherjee R. Serum potassium and clinical outcomes in the Eplerenone Post-Acute Myocardial Infarction Heart Failure Efficacy and Survival Study (EPHESUS). Circulation. 2008;118(16):1643-1650.

110. Jessup M, Abraham WT, Casey DE, et al. 2009 Focused update: ACCF/ AHA guidelines for the diagnosis and management of heart failure in adults: a report of the American College of Cardiology Foundation/American Heart Association Task Force on Practice Guidelines. Circulation. 2009;119(14):1977-2016.
111. Epstein M, Calhoun DA. Aldosterone blockers (mineralocorticoid receptor antagonism) and potassium-sparing diuretics. $J$ Clin Hypertens (Greenwich). 2011;13(9):644-648.

112. Lentini S, Heinig R, Kimmeskamp-Kirschbaum N, Wensing G. Pharmacokinetics, safety and tolerability of the novel, selective mineralocorticoid receptor antagonist finerenone: results from firstin-man and relative bioavailability studies. Fundam Clin Pharmacol. 2016;30(2):172-184.

113. Bogman K, Schwab D, Delporte ML, et al. Preclinical and early clinical profile of a highly selective and potent oral inhibitor of aldosterone synthase (CYP11B2). Hypertension. 2017;69(1):189-196.

114. Calhoun DA, White WB, Krum H, et al. Effects of a novel aldosterone synthase inhibitor for treatment of primary hypertension: results of a randomized, double-blind, placebo- and active-controlled phase 2 trial. Circulation. 2011;124(18):1945-1955.

115. Shibata H, Itoh H. Mineralocorticoid receptor-associated hypertension and its organ damage: clinical relevance for resistant hypertension. Am J Hypertens. 2012;25(5):514-523.

116. Kashiwagi Y, Mizuno Y, Harada E, et al. Suppression of primary aldosteronism and resistant hypertension by the peroxisome proliferatoractivated receptor gamma agonist pioglitazone. Am J Med Sci. 2013;345(6):497-500.

117. Liu G, Zheng XX, Xu YL, Lu J, Hui RT, Huang XH. Effect of aldosterone antagonists on blood pressure in patients with resistant hypertension: a meta-analysis. J Hum Hypertens. 2015;29(3):159-166.

118. Dahal K, Kunwar S, Rijal J, et al. The effects of aldosterone antagonists in patients with resistant hypertension: a meta-analysis of randomized and nonrandomized studies. Am J Hypertens. 2015;28(11):1376-1385.

119. Guo H, Xiao Q. Clinical efficacy of spironolactone for resistant hypertension: a meta analysis from randomized controlled clinical trials. Int J Clin Exp Med. 2015;8(5):7270-7278.

120. Hwang AY, Dave C, Smith SM. Trends in antihypertensive medication use among US patients with resistant hypertension, 2008 to 2014 Hypertension. 2016;68(6):1349-1354.
Vascular Health and Risk Management

\section{Publish your work in this journal}

Vascular Health and Risk Management is an international, peerreviewed journal of therapeutics and risk management, focusing on concise rapid reporting of clinical studies on the processes involved in the maintenance of vascular health; the monitoring, prevention and treatment of vascular disease and its sequelae; and the involvement of

\section{Dovepress}

metabolic disorders, particularly diabetes. This journal is indexed on PubMed Central and MedLine. The manuscript management system is completely online and includes a very quick and fair peer-review system, which is all easy to use. Visit http://www.dovepress.com/ testimonials.php to read real quotes from published authors. 